\title{
Contextualizing Western guidelines for stroke and low back pain to a developing country (Philippines): an innovative approach to putting evidence into practice efficiently
}

This article was published in the following Dove Press journal:

Journal of Healthcare Leadership

9 October 2012

Number of times this article has been viewed

\author{
Consuelo B Gonzalez- \\ Suarez ${ }^{1,2,3}$ \\ Karen Grimmer-Somers' \\ Janine Margarita Dizon' \\ Ellena King' \\ Sylvan Lorenzo ${ }^{2}$ \\ Carolina Valdecanas ${ }^{2}$ \\ Ephraim Gambito² \\ Belinda Fidel ${ }^{2,3}$ \\ 'International Center for Allied \\ Health Evidence, University of \\ South Australia, Adelaide, Australia; \\ 2Philippine Academy of Rehabilitation \\ Medicine, Quezon City, Philippines; \\ ${ }^{3}$ University of Santo Tomas, Manila, \\ Phillipines
}

Background: High-quality evidence-based clinical guidelines are widely available for many diseases. Clinical guidelines support evidence-based care decisions and improved health outcomes. Most clinical practice guidelines have been developed in the Western world and reflect a developed country's health systems and services, disease epidemiology, and workforce. Such guidelines are therefore not immediately relevant or generalizable to developing countries. Guidelines are expensive to produce, and it is more resource efficient for developing countries to contextualize available Western guidelines, rather than develop their own. This paper describes a leadership initiative by the Philippines Association of Rehabilitation Medicine to contextualize high-quality relevant Western guidelines for local management of stroke and low back pain.

Methods: Twenty-one steps were developed, covering initial training and establishing the framework within which recommendations were contextualized; then guideline searching, critiquing, and including; and then contextualization, review, and implementation. A writing guide assisted the group to endorse recommendations in a standard manner, relevant to a "typical" patient journey, and to contextualize recommendations for local settings.

Results: Recommendations were extracted from eight low back pain and five stroke clinical guidelines. Philippines Association of Rehabilitation Medicine endorsements were made, reflecting summarized recommendations and underpinning strength of the evidence body. Philippines Association of Rehabilitation Medicine context points contextualized the recommendations in terms of local health service delivery.

Conclusion: A systematic reproducible process was applied to contextualize high-quality, relevant Western guidelines for immediate application to one developing country. This approach focused resources on contextualization, implementation, and uptake rather than de novo development. This leadership initiative offers a resource efficient way to implement evidence-based practice in developing countries when there is neither time nor resources for de novo guideline development.

Keywords: PARM, clinical guidelines, Philippines, endorsements, context points, evidencebased practice

\section{Background}

\section{Clinical guidelines supporting evidence-based practice}

"Clinical practice guidelines are systematically developed statements to assist practitioner and patient decisions about appropriate health care for specific clinical circumstances." ${ }^{\prime}$ Over the last 15 years, well-credentialed guideline development groups 
have set international standards for guideline construction (eg, Scottish Intercollegiate Guidelines Network, New Zealand Guidelines Group, Australia's National Health and Medical Research Council [NHMRC] and the United Kingdom's National Health Service's National Institute for Clinical Excellence). ${ }^{2-5}$ These groups provide policy makers, managers, health care providers, and patients with ready access to high-quality clinical guidelines on a range of topics.

Essential components of guideline development include systematic literature searches, clear inclusion and exclusion criteria, and evidence appraisal. However, despite international investment in this process, there remains a lack of detail in how guidelines should be developed, the evidence reported, and recommendations worded. ${ }^{6}$ Moreover, there is inconsistent nomenclature, where terms such as guidelines, recommendations, care pathways, and protocols have different meaning in different settings. ${ }^{7}$ Critical appraisal tools such as AGREE (Appraisal of Guidelines Research and Evaluation) provide criteria to assess the independence of guideline developers, the clarity of guideline purposes, the scope and end-users, the transparency of clinical questions, how the literature was searched, appraised, extracted, and synthesized, how recommendations were worded, and how guidelines were revised. ${ }^{8}$

The GuideLine Implementability Appraisal group provides advice on wording guideline recommendations to reflect the strength of the underpinning evidence. ${ }^{9}$ This encourages guideline users to implement the recommendations which have the strongest underpinning evidence. The ADAPTE collaboration (from Canada and Europe) reports on processes to adapt a guideline from one setting to another. ${ }^{10}$ This group also provides guidance on how to layer the evidence cited in old guidelines, with more recently published evidence. There is emergent literature on adapting guideline recommendations from one environment to another. ${ }^{11}$ However, to date it appears from the current search of the literature that guideline adaptation has been undertaken only in Western countries. No framework could be found to assist in putting Western guidelines into context for resource-limited low- and middle-income countries with different health care systems, health care provider relationships, education, and patient needs. For this reason, the authors propose an innovative, simple, and practical approach to contextualizing guidelines from high-income countries for a middle-income country (the Philippines).

There is also no widely accepted approach to reporting the strength of the body of evidence underpinning guideline recommendations. Consequently, the key guideline development groups use different approaches, such as providing summaries of the evidence, reporting the hierarchy and/or methodological quality, simply providing reference lists, or giving a considered judgment of the strength of the body of evidence using a ranking (letter or number). The Grades of Recommendation, Assessment, Development, and Evaluation group and Australia's NHMRC FORM approach provide suggestions as to how to assess and summarize the strength of the body of evidence for each guideline recommendation. ${ }^{12,13}$

\section{Translating guidelines into practice}

There is an increasing body of research regarding best practice in guideline implementation. This research highlights that no matter how well a guideline is constructed, it will not implement itself. ${ }^{14,15}$ Strong and informed leadership that plans and implements multipronged evidence-translation approaches is required to embed guideline recommendations into widespread and sustainable local practice. ${ }^{16}$

This paper reports the first work - to the authors' knowledge - of a professional medical association taking a leadership approach to contextualizing currently available guidelines to the needs of a developing country that is only now adopting evidence into its health care delivery. The Philippine Academy of Rehabilitation Medicine (PARM) worked on this project using PARM project leaders, mentorship from a collaborating Australian university, and dedicated volunteers in small working groups.

\section{Adaptation versus contextualization}

The first challenge was to describe what was being done in locally understandable terms. Evidence-based practice is a new concept in the Philippines and thus there was limited local capacity or knowledge regarding guideline development. The ADAPTE framework proposes a framework for adaptation of existing guidelines to new (but similar) environments. ${ }^{10,11}$ However, this framework was not suitable, as an efficient way of putting existing guideline recommendations to work in an environmentally, socially, politically, and economically different context was required. The Encarta English dictionary defines adapt as to change something to suit different conditions or a different purpose, or be changed in this way, whilst contextualize is to place a word, phrase, or idea within a suitable context. ${ }^{17}$ Therefore, adaptation (as proposed by the ADAPTE framework) ${ }^{10,11}$ and contextualization are not synonymous. Consequently, the PARM group worked on the premise that contextualizing 
a guideline for use in developing countries meant retaining its current form, and writing strategies that assisted in its operationalization in the local environment. This process would not involve any de novo guideline development steps, rather the work would focus on how to best translate existing evidence statements into local practice.

Guideline writing involves semantics, where the best words are chosen to translate evidence into persuasive and adoptable clinical recommendations. ${ }^{5-9}$ The purpose behind the current work was to ensure that existing high-quality recommendations could be readily implemented by Filipino health care providers by putting them into local contexts and demonstrating their relevance, using practical strategies. The contextualization process fills the gap between expected (evidence-based) practice and "typical" Filipino practice by:

a. Providing a PARM writing guide to standardize the contextualization process.

b. Providing recommended wording (PARM endorsements) to underpin summaries of relevant guideline recommendations and their underpinning strength of evidence, embedded in a typical patient journey. This would assist Filipino health care stakeholders (policy makers, managers, rehabilitation doctors, general medical practitioners, other specialists, and allied health) to readily adopt current best available evidence.

c. Providing PARM context points that offer practical guidance and strategies to support Filipino health care stakeholders to do the best they can to put current best evidence into practice within the constraints of their local resources and environment.

Thus, there was no intent to adapt existing guideline recommendations by rewording, revising, or updating the evidence, as this process would not have achieved the aim of this work. There was a far more urgent need to implement existing evidence widely to educate health care providers about evidence-based guidelines, improve local practices, and make the best of available resources. Thus, the intention in contextualizing existing recommendations was to make it simple for Filipino health care stakeholders who knew little about evidence-based practice or guideline development to provide the best possible health care, with minimum training and least expense, in any environment and for any patient.

\section{A developing country context.... the Philippines}

The Philippines is a developing Southeast Asian country, with limited health resources within its total budget to meet its people's needs. Filipino health care services can vary enormously, depending on their location, across the 7000 islands in the nation. Health care could be provided in metropolitan, regional, urban, rural, or very remote settings. In 2009, government expenditure on health in the Philippines was approximately $3.4 \%$ of the gross domestic product, with total per year expenditure on health per capita around US\$153. ${ }^{18}$ By comparison, in Australia in 2009, the percentage government expenditure was approximately $8.5 \%$ of gross domestic product, with per capita health expenditure approximately US $\$ 3300 .{ }^{19}$ Given the limited resources available in the Philippines for health care, it is therefore essential that scarce resources are used wisely to obtain optimal and equitable health and service outcomes. In response to this, the Department of Health in 2005 launched the FourMula ONE for Health as the implementation framework for the Health Sector Reform Agenda of the Philippine government. It created a policy on establishing a continuing quality improvement program and committee in Department of Health hospitals, which advocates the use of clinical practice guideline. ${ }^{20}$ However, in the review of the Philippine Health Insurance Corporation, a larger share of the funds of the government for the continuing quality improvement program is being taken by the development of de novo clinical practice guidelines and not to its dissemination and implementation.

\section{PARM}

PARM is the national Filipino society of physiatrists. Physiatrists are involved in the management of physical disorders that limit participation of individuals in activities of daily living and vocational and avocational activities. Their primary objectives are to optimize patients' functional activities and quality of life. The disorders referred to physiatrists are neuromuscular disorders such as stroke, spinal cord injury, and cerebral palsy, orthopedic conditions such as amputation and sports injury, cardiopulmonary diseases, and musculoskeletal pain syndromes such as low back and neck pain. However, stroke and low back pain are two of the most common conditions referred to rehabilitation medicine.

According to the Department of Health, vascular disease is the second highest cause of morbidity in the Philippines. ${ }^{21}$ The prevalence of stroke in the Philippines has increased in recent years, affecting more people at younger ages, and causing a large burden on the Filipino health care system. Residual deficits of stroke may include hemiplegia, spasticity, and dysphagia, which are treated by physiatrists and paramedical personnel such as physical, occupational, and speech therapists. 
A recent study by $\mathrm{Lu}$ and Javier showed that $13.6 \%$ of adult Filipinos suffer from chronic pain, and $21 \%$ of those afflicted with chronic pain reported having low back pain. ${ }^{22}$ It is believed to be the most common cause of decreased productivity among the working population and 11.4 working days have been lost in the past 6 months in adult Filipinos suffering from chronic pain. The persistent and/or recurrent nature of low back carries with it the propensity to incur high costs of treatment, notwithstanding the need for immediate relief from pain and discomfort to improve function and prevent disability. There are still no standardized guidelines in the Philippines being utilized to treat these conditions. If relevant guidelines were available for Filipino health care settings, they could assist in improving local service delivery and health outcomes. Providing evidence-based health care is one way of minimizing harm, limiting underuse, overuse, and misuse of health care, and improving cost-effectiveness. ${ }^{6}$ If Filipino-contextualized clinical guidelines were available to all Filipino health care providers for common Filipino health conditions, evidence-based practice could be more broadly promoted, and resources used more effectively and efficiently. Thus, these two conditions were adopted as vehicles for the initial PARM process of guideline contextualization.

\section{Methods}

\section{Guideline working groups}

Two PARM working groups were established (total of 26 PARM fellows and associate members). Members were invited for their research background and willingness to voluntarily participate in this first known Filipino attempt at guideline contextualization. There were 21 steps in the process, outlined in Figure 1.

\section{Getting started (1.5-day workshop and planning session)}

1. Training: short updates by a visiting scholar (KG-S) and one of the team (JMD) were provided to the group on broad principles of evidence-based practice, guideline development methodology, guideline searching and critical appraisal, and issues of guideline implementation.

2. Construct typical patient journeys: a PARM vision for Filipino contextualization of existing clinical guidelines was established, with the focus being on generalizability and applicability of existing guideline recommendations for stroke and low back pain, relevant to typical Filipino patient journeys. Typical patient journeys were then constructed to ensure that all important steps - from first presentation to a health care provider to discharge from health care services - were identified. This involved much activity and discussion, with white boards and butcher paper, allowing the participants to discuss, understand, and map just what could (and did) happen to patients from onset of disease to long-term management in the community or discharge from services.

3. Establish scope and purpose: the scope, purpose, and endusers of Filipino-contextualized guidelines for stroke and low back pain were debated, relevant to Filipino stroke and low back pain patient journeys. The journeys were revised to encompass the different Filipino health care settings to which patients might present, and the range of health care providers and resources that they might access.

4. Working groups: the PARM working groups were then divided into smaller groups of one or two people, who worked on specific sections of the patient journeys. Monthly meetings were held and the small groups presented work to date to the other members of the working group, including recommendations that had been extracted from the included guidelines (relevant to the Filipino patient journey), summaries of the underpinning strength of the body of evidence for the extracted recommendations, and draft PARM endorsements and PARM context points.

\section{During the 8 months following the workshop}

Systematic search, appraisal, and synthesis

of the evidence

5. Search for appropriate guidelines: the PARM group searched the websites of well-credentialed guideline developers (Scottish Intercollegiate Guidelines Network, New Zealand Guidelines Group, NHMRC, National Institute for Clinical Excellence), ${ }^{2-5}$ as well as the National Guideline Clearinghouse site, ${ }^{23}$ to identify potentially useful guidelines for stroke and low back pain. Search terms included: "clinical guidelines AND stroke OR CVA" and "clinical guidelines AND low back pain OR LBP'. Further searching was undertaken using www.google.com, as guidelines are often published on government department or industry websites.

6. Screen guidelines for relevance to scope, purpose, and patient journeys: the purpose, scope, and end-users of these guidelines were examined, and those which were congruent with the purpose, scope, and end-users of the proposed Filipino guidelines and relevant to the patient journeys were considered for inclusion. 


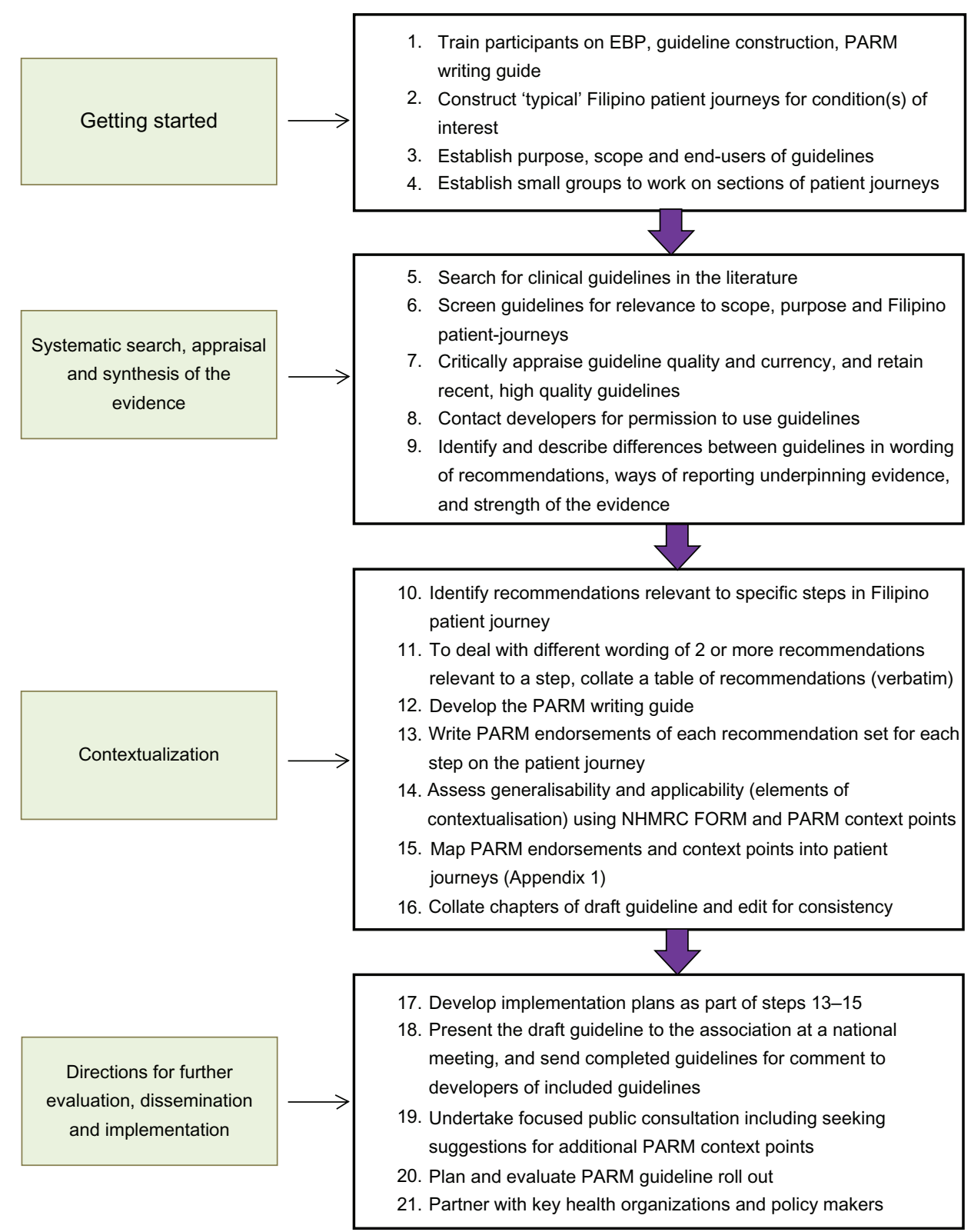

Figure I The Filipino guideline contextualization process used by the Philippine Academy of Rehabilitation Medicine.

Abbreviations: EBP, evidence-based practice; PARM, Philippine Academy of Rehabilitation Medicine; NHMRC, Australia's National Health and Medical Research Council.

7. Critically appraise guideline quality and currency: the guidelines under consideration were then critically appraised using the International Center for Allied Health Evidence guideline checklist,${ }^{24}$ and the most recent guidelines with the highest quality were retained.

8. Obtain permission: the PARM group contacted the developers of the included guidelines for permission to cite relevant recommendations. The working groups outlined the purpose of their contextualization project, and made it clear that no changes would be made to the wording of their recommendations, or to the evidence base of the published guidelines. The draft final guidelines were to be returned to the source guideline developers for formal review and approval.

9. The group then identified and described as a matrix differences between the included guidelines in wording of recommendations, ways of reporting underpinning evidence, and strength of evidence. This matrix would form the basis for collating relevant recommendations in later steps.

\section{Contextualization}

10. Extract and summarize recommendations (and their underlying evidence body) into the patient journey: the 
working groups extracted relevant recommendations from each included guideline, related to the Filipino patient journey, for stroke or low back pain. The groups used the matrix developed in Step 9 as a guide.

11. Dealing with different wording of recommendations: multiple relevant recommendations were often found across the source guidelines for particular aspects of the patient journey. Whilst these recommendations were often based on the same evidence sources, the wording frequently differed, as did ways of reporting the underpinning evidence strength. All relevant recommendations and their accompanying summaries of the strength of the evidence were therefore collated (verbatim) into tables. These were then matched to the matrix developed in Step 9.

12. Develop a writing guide to endorse and contextualize recommendations: a guide for writing PARM endorsements and PARM context points was developed. The PARM endorsements (summary statements which addressed multiple recommendations) used specific wording to reflect the strength of the underpinning evidence, based on GuideLine Implementability Appraisal and NHMRC., ${ }^{9}$ Practice points (or similar nomenclature) are a common feature of guidelines. However, they are used in different ways by guideline developers. Practice points can refer to the deliberations of an expert working party in the absence of published evidence, or where the evidence is weak or contradictory. In other instances, practice points refer to operationalization of guideline recommendations ("how to do it"). The PARM group used PARM context points as strategies to bridge the gap between evidence-based recommendations and typical Filipino practice, to provide guidance for typical clinicians treating typical patients. They ranged from training required by health care providers to implement recommendations, how to use alternative resources, how to build multidisciplinary teams and improve quality and timeliness of referrals, and/or how to ensure equity of health care access and services throughout the Philippines.

13. Using the PARM writing guide, the working group then drafted PARM endorsements and PARM context points for each set of recommendations relevant to the patient journey.

14. Assess generalizability and applicability of recommendations to Filipino situations: PARM applied the fourth and fifth elements of the NHMRC FORM tool ${ }^{13}$ to assess the generalizability and applicability of the included recommendations to Filipino settings. There was no consideration of the first three FORM elements of evidence strength (evidence base, consistency, and clinical impact) for any included guideline, as to do so would have violated the PARM contextualization process. Moreover, the PARM group did not assign an evidence level (A-D) to generalizability and applicability of any PARM endorsement, as this grading is the basis of the FORM guide for de novo guideline development. ${ }^{8}$ Rather, PARM focused on discussion of generalizability and applicability of summarized recommendations to determine whether PARM endorsement was sufficient to guide practice decisions, or whether PARM context points were also required to contextualize the endorsed recommendation(s) within the patient journey. When there was confusion in interpreting recommendations to the Filipino patient journey, or when the included guideline recommendations were contradictory, the group went back to the original references for clarification. If required, the level of the PARM endorsement was debated and consensus arrived at, with a final decision from the working group chair in the absence of consensus.

15. Map the PARM endorsements, context points, and tables of collated recommendations and references into the patient journeys: the PARM group mapped the PARM endorsements, PARM context points, and tables of collated recommendations and references, including the collated strength of body of evidence, into the Filipino patient journeys for stroke and low back pain. For ease of reading, the tables of extracted guideline recommendations and accompanying summaries of the strength of body of evidence were provided as supporting documentation.

16. Editing: the chapters of the draft guidelines were collated and edited for consistency.

\section{Implementation}

17. Develop an implementation plan: concurrent with the PARM contextualization process, implementation plans were established based on the findings of recent systematic reviews. ${ }^{25,26}$ These reviews consistently indicate that multipronged strategies are required to ensure that the guideline recommendations are disseminated in a manner that addresses health professionals' current knowledge base, learning styles, and work environments. PARM agreed that the key to successful guideline uptake by physiatrists was "selling" the notion of using evidence to underpin Filipino best practice. 
18. Dissemination: the draft PARM guidelines for stroke and low back pain were initially presented to the PARM annual convention in February 2012, to elicit much discussion on the novelty of the processes.

19. Public consultation: the guidelines are currently under national public consultation. The public consultation step has two purposes. Firstly, to obtain general feedback on the wording and practicality of the recommendations and PARM context points prior to dissemination, and secondly, as a dissemination strategy to increase health provider awareness of the process and availability of clinical guidelines contextualized for Filipino settings. The supporting Australian research center (International Center for Allied Health Evidence, Adelaide, Australia) is providing editorial support, and independently managing the public consultation process.

20. Guideline rollout: there was agreement at the national convention that the Filipino-contextualized guidelines would be disseminated to health care providers throughout the Philippines who treat stroke and low back pain, using simple-to-navigate short forms, peer leaders, change champions from within the organization,
Table I Scope and purpose of the treatment of low back pain and stroke rehabilitation

\section{Low back pain}

I. Identify appropriate clinical and diagnostic approaches to the evaluation of low back pain.

2. Determine rational pharmacologic and nonpharmacologic treatment strategies for low back pain based on current evidence, aimed at improving primary outcomes and reducing disability.

3. Establish criteria for referral to other specialists as necessary for further management and focused care.

\section{Stroke rehabilitation}

I. Improve outcome measures of stroke patients (mobility, activities of daily living, return to work).

2. Ensure that all stroke patients receive early active and effective rehabilitation via dedicated stroke teams. Available health systems should have comprehensive services which include and link the fundamentals of acute and chronic rehabilitation care.

3. Prevent the recurrence of stroke through appropriate and effective treatment strategies.

and incentives to apply the guidelines. The process and outcome of contextualizing high-quality, relevant, current international clinical guidelines for low back pain and stroke will be evaluated through the public consultation focus, and also by focus groups of the PARM working

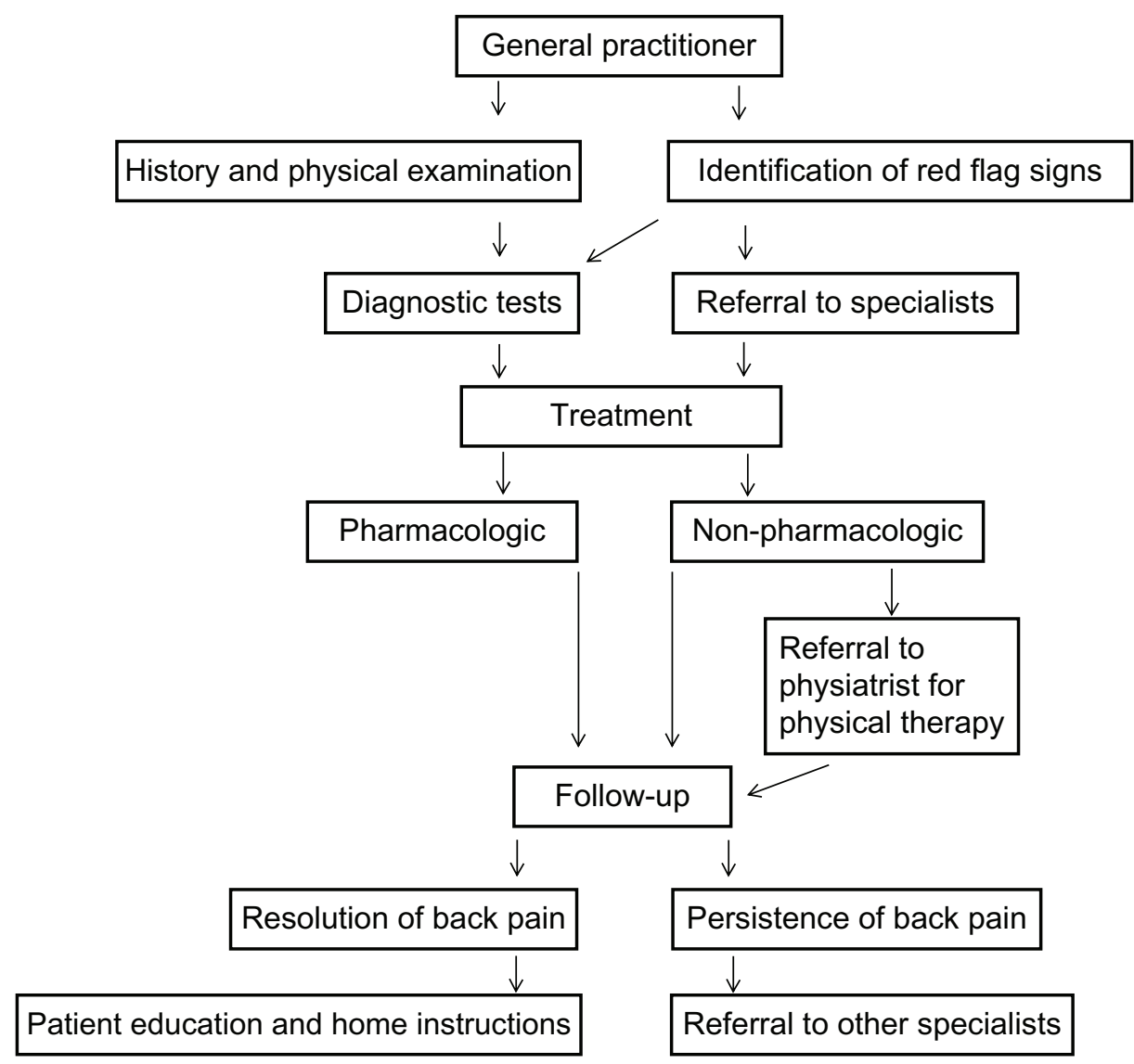

Figure 2 A typical patient journey including the evaluation, diagnosis, and treatment of patients with low back pain. 
groups and the broader PARM membership. Focus groups will identify opportunities for improving the guideline contextualization process, streamlining voluntary effort for future guideline contextualization processes, modifying the PARM writing guide, and ensuring that other locally relevant guidelines based on current best evidence can be prioritized and developed efficiently. Likewise, plans to minimize the barriers to implementation and acceptance identified by the Philippine Health Insurance Corporation will be discussed. These would include the following: lack of awareness and agreement with the clinical practice guidelines, inability to overcome the inertia of current practice, fear of stereotyping patient care, fear of using clinical practice guidelines in malpractice litigation cases, and lack of adequate infrastructure in disseminating clinical practice guidelines. ${ }^{27}$

21. Establish partnerships: partnerships will be forged by PARM with Filipino policy makers, national health councils and organizations, and other health associations to support putting the PARM contextualized guidelines into widespread practice.

Stroke patient admitted in the hospital (intensive care unit, stroke unit)

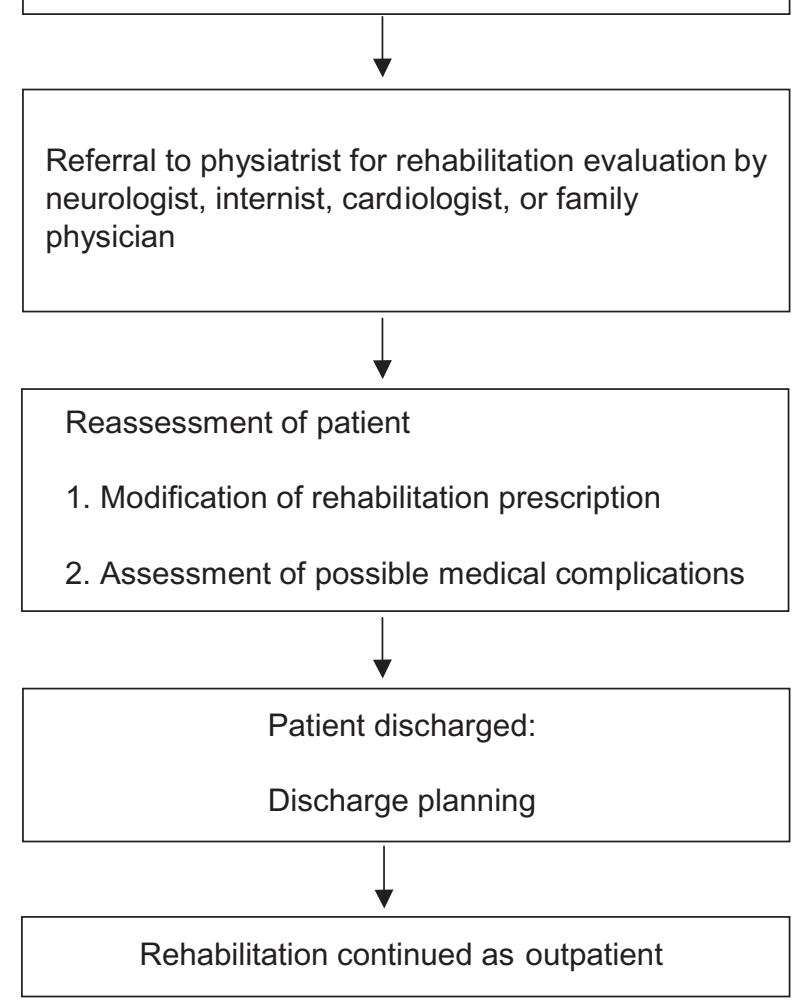

Figure 3 A typical patient journey for the rehabilitation of stroke patients in hospital settings.

\section{Results}

\section{Scope, purpose, and patient's journey}

The scope, purpose, and end-users of the Filipinocontextualized guidelines were deliberated and agreed upon by the PARM working groups (Table 1). The end-users for the low back pain guidelines were physiatrists while the referring physicians handling stroke patients and the medical and allied health professionals providing rehabilitation care were the end-users for the stroke rehabilitation clinical guidelines.

The patient's journey for treatment of low back pain and stroke rehabilitation are seen in Figures 2-4.

Patient referred at outpatient rehabilitation clinic

\begin{tabular}{|l|}
\hline Rehabilitation evaluation by physiatrist \\
\hline Treatment given to patient: \\
Physical therapy \\
Occupational therapy \\
Speech therapy \\
Reassessment by physiatrist for: \\
1. Modification of rehabilitation prescription \\
2. Need for assistive device \\
3. Need for splint and orthosis \\
4. Fall assessment \\
\hline
\end{tabular}

Figure $4 \mathrm{~A}$ typical patient journey for rehabilitation of stroke patients in outpatient settings. 
Treatment of these two conditions necessitates the involvement of multidisciplinary treatment of both medical and paramedical personnel.

\section{Systematic search, appraisal, and synthesis of the evidence}

Eight possibly relevant clinical practice guidelines for the treatment of low back pain and seven clinical practice guidelines for stroke rehabilitation were identified. Two stroke guidelines were excluded: the Scottish Intercollegiate Stroke Working Party guideline because no level of evidence was given for each recommendation, and the Ottawa Panel stroke guideline because it did not meet more than $50 \%$ of the methodological assessment criteria. ${ }^{28,29}$ Eight low back pain guidelines and five stroke guidelines were included (Table 2).

Because of the differences between guidelines regarding the style of reporting recommendations, particularly regarding how information on the underpinning evidence and strength of evidence were presented, a matrix was formulated to assist the PARM working groups to standardize the process of guideline contextualization. The parameters that were taken into account were the quality of evidence, the uniformity of thought, consistency of the grades of evidence, the volume of literature underpinning the recommendations, and the age of the references.

The quality of evidence was graded high, moderate, or low. High-quality evidence could be variously described as levels I or II/A or B in the guidelines. If the evidence was graded as either level II or III/B or C, it was classified as moderate-quality evidence. Low-quality evidence was described as level III or IV/C or D. Uniformity of thought was graded as uniform or variable based on similarity of the findings of the different clinical practice guidelines as to the effectiveness or ineffectiveness of a treatment modality and reliability of diagnostic procedure or physical examination. The level of evidence was rated as consistent or inconsistent based on the homogeneity of the evidence level assigned by the different clinical practice guidelines. The volume of references was graded as low if the number of references was less than or equal to three, moderate if the number was between four and seven, and high if the volume was greater than eight. The age of the references was assessed as current if $50 \%$ of the papers cited were

Table 2 Clinical guidelines included in the guideline contextualization for implementation in the developing counties by the Philippine Academy of Rehabilitation Medicine

\section{Low back pain}

I. Negrini S, Giovannoni S, Minozzi S, et al. Diagnostic therapeutic flow-charts for low back pain patients: the Italian clinical guidelines. Eura Medicophys. 2006;42(2):151-170. ${ }^{33}$

2. National Institute for Health and Clinical Excellence. Low back pain: early management of persistent non-specific low back pain. May 2009. Available from: http://publications.nice.org.uk/low-back-pain-cg88. Accessed March I5, 20I2. ${ }^{34}$

3. Toward Optimized Practice. Guideline for the evidence-informed primary care management of low back pain. 2009. Available from: http://www. topalbertadoctors.org/cpgs.php?sid=65\&cpg_cats=90. Accessed March 15, 2012.35

4. Montreal Public Health Department. CLIP practice guideline: clinic on low-back pain in interdisciplinary practice. 2007. Available from: http:// collections.banq.qc.ca/ark:/52327/bs47I25. Accessed March 15, 2012.36

5. Institute for Clinical Systems Improvement. Health care guideline: adult acute and subacute low back pain. January 20I2. Available from: http:// www.icsi.org/low_back_pain/adult_low_back_pain_8.html. Accessed March I5, 20I2. ${ }^{37}$

6. WorkCoverSA. Acute-subacute low back pain. 2010. Available from: http://www.workcover.com/site/treat_home/guidelines_by_injury_type/ acutesubacute_low_back_pain.aspx. Accessed March 15, 2012.38

7. Chou R, Qaseem A, Snow V, et al. Diagnosis and treatment of low back pain: a joint clinical practice guideline from the American College of Physicians and the American Pain Society. Ann Intern Med. 2007; I47(7):478-491.39

8. Chou R, Loeser J, Owens D, et al. Interventional therapies, surgery, and interdisciplinary rehabilitation for low back pain: an evidence-based clinical practice guideline from the American Pain Society. Spine (Phila Pa 1976). 2009;34(I0): 1066-1077.40

Stroke rehabilitation

I. Canadian Stroke Strategy. Canadian best practice recommendations for stroke care (update). December 8, 20I0. Available from: http://www.hsf. sk.ca/siss/documents/2010_BP_ENG.pdf. Accessed March I5, 2012.41

2. National Stroke Foundation - Australia. Clinical guidelines for stroke management. 20I0. Available from: http://strokefoundation.com.au/healthprofessionals/tools-and-resources/clinical-guidelines-for-stroke-prevention-and-management/. Accessed March I5, 20I2.42

3. Scottish Intercollegiate Guidelines Network. Management of patients with stroke: rehabilitation, prevention and management of complications, and discharge planning. 2010. Available from: http://www.sign.ac.uk/guidelines/fulltext/I I8/index.html. Accessed March 15, 2012.43

4. Scottish Intercollegiate Guidelines Network. Management of patients with stroke: identification and management of dysphagia. 20I I. Available from: http://www.sign.ac.uk/guidelines/fulltext/II9/index.html. Accessed March 15, $2012 .{ }^{44}$

5. Department of Veterans Affairs; Department of Defense; American Heart Association; American Stroke Association. Management of stroke rehabilitation. 2010. Available from: http://www.healthquality.va.gov/stroke/stroke_full_22I.pdf. Accessed March 15, 2012.45 
Table 3 Philippine Academy of Rehabilitation Medicine guide for summarizing the strength of evidence

\begin{tabular}{|c|c|}
\hline I. There is strong evidence & $\begin{array}{l}\text { Consistent grades of high-quality evidence with uniform thought, }{ }^{\dagger} \text { and at least a moderate volume of references } \\
\text { to support the recommendation(s) }\end{array}$ \\
\hline \multirow[t]{7}{*}{ 2. There is evidence } & A mix of moderate- and high-quality evidence with uniform thought and at least a low volume of references \\
\hline & OR \\
\hline & A mix of high- and low-quality evidence with uniform thought and high volume of references \\
\hline & OR \\
\hline & High-level evidence coupled with GPPs, and at least moderate volume of references \\
\hline & OR \\
\hline & One level I paper with at least moderate volume of references \\
\hline \multirow[t]{5}{*}{ 3. There is some evidence } & Single level II (A) paper \\
\hline & OR \\
\hline & Inconsistent grades of high and low evidence with uniform thought and moderate volume of references \\
\hline & OR \\
\hline & Consistent grades of low-level evidence with uniform thought and at least a moderate volume of references \\
\hline 4. There is conflicting evidence & A mix of levels of evidence with nonuniform thought, irrespective of the volume of evidence \\
\hline 5. There is insufficient evidence & Low or inconsistent levels of evidence with low volume references with or without GPPs \\
\hline 6. There is no evidence & Absence of evidence for any aspect of the patient journey \\
\hline
\end{tabular}

Notes: Hniform thought was the term coined by the Philippine Academy of Rehabilitation Medicine group to identify when differently worded recommendations from different guidelines had the same intent. This assisted Philippine Academy of Rehabilitation Medicine to resolve the issue of different wording of recommendations, despite using the same underpinning references.

Abbreviation: GPP, good practice point.

published later than 2006 and noncurrent if the majority of the papers were published prior to 2006. There are six levels of evidence based on the above parameters which ranged from having strong evidence to having no evidence. Table 3 provides the levels of evidence for summarizing the strength of the body of evidence for the recommendations. Table 4 presents the guide on writing the endorsements based on the strength of evidence.

The PARM context points considered aspects specified within the Donabedian quality framework (structure, process) in order to define the important elements of service delivery underpinning evidence-based care ${ }^{30}$ This assisted the PARM working groups to take into account issues such as training of health care providers to comply with recommendations, availability of, and access to trained health care providers across the Philippines, access to appropriate diagnostic and

Table 4 Philippine Academy of Rehabilitation Medicine guide for writing endorsements

$\begin{array}{ll}\begin{array}{l}\text { I. PARM strongly } \\ \text { endorses }\end{array} & \begin{array}{l}\text { When there is strong evidence as } \\ \text { determined by the criteria in Table } 3 \\ \text { 2. PARM endorses }\end{array} \\ \begin{array}{ll}\text { When there is evidence as determined by } \\ \text { the criteria in Table } 3\end{array} \\ \text { 3. PARM recommends } & \begin{array}{l}\text { When there is some evidence as determined } \\ \text { by the criteria in Table } 3\end{array} \\ \text { When there is conflicting evidence or } \\ \text { PARM suggests } & \begin{array}{l}\text { insufficient evidence as determined by the } \\ \text { criteria in Table } 3\end{array} \\ & \text { There is insufficient or no evidence as } \\ \text { 5. PARM does not } & \text { determined by the criteria in Table } 3 \\ \text { endorse } & \end{array}$

Abbreviation: PARM, Philippine Academy of Rehabilitation Medicine. assessment processes, availability of resources and what to do when resources are unavailable, and alternative diagnostic or management approaches which could be adopted in the absence of capacity to provide guideline recommended health care. This process of contextualizing recommendations to local conditions addresses the fourth pillar of evidence-based practice as discussed by Hoffmann et al (the other pillars being the research evidence, clinician reasoning, and patient choice). ${ }^{31}$

To assist in writing the PARM context points, a standard framework was developed, which outlined the elements which need to be in place for minimum best practice care to be provided equitably across the Philippines. Elements which addressed additional standard care of practice were also considered in this framework. This provides guidance to clinicians wherever they may practice in the Philippines regarding essential equipment, standards, and resources, training, and workforce in order to provide evidencebased care.

\section{Contextualization}

The guide developed for writing PARM strength of evidence, recommendations writing PARM endorsements, and PARM context points was utilized to write the set of recommendations relevant to the patient journey. An example is provided in Table 5, which relates to the intensity and duration of rehabilitation for stroke. Guidelines universally recommend that patients are provided with daily therapy to optimize rehabilitation outcomes. However, in the 
Table 5 Philippine Academy of Rehabilitation Medicine summarized recommendations and endorsement regarding the intensity and duration of rehabilitation for stroke patients

\begin{tabular}{|c|c|c|c|}
\hline Recommendation & Guideline & Body of evidence & Reference \\
\hline \multicolumn{4}{|c|}{ Consistent level of evidence - high volume - noncurrent - uniform thought } \\
\hline There is strong evidence that patients should be mobilized as early and as & NSF & B & Bernhardt et al $2008^{46}$ \\
\hline frequently as possible once medical stability is reached, preferably within & SIGN (2010) & $\mathrm{B}, \mathrm{I}+$ & Langhorne et al $2007^{47}$ \\
\hline \multicolumn{4}{|l|}{24 hours of stroke symptom onset unless contraindicated. } \\
\hline & USVA/Dod & $A, I$ & Cifu and Stewart $1999^{48}$ \\
\hline & & & Gagnon et al $2006^{49}$ \\
\hline & & & Ottenbacher and Jannell $1993^{50}$ \\
\hline & & & Maulden et al $2005^{51}$ \\
\hline & & & Musicco et al $2003^{52}$ \\
\hline & & & Paolucci et al $2000^{53}$ \\
\hline & & & Wade et al $1992^{54}$ \\
\hline & CSS & B & Sorbello et al $2009^{55}$ \\
\hline \multicolumn{4}{|l|}{ Consistent level of evidence - low volume - noncurrent - uniform thought } \\
\hline There is evidence that the patient should receive as much therapy & USVA/Dod & B & Kwakkel et al $1999^{56}$ \\
\hline as "needed" and tolerated, to adapt, recover, and/or reestablish the & & & Langhorne et al $1996^{57}$ \\
\hline $\begin{array}{l}\text { premorbid or optimal level of functional independence. } \\
\text { Consistent level of evidence }- \text { high volume }- \text { noncurrent - uniforn }\end{array}$ & \multicolumn{2}{|c|}{ Consistent level of evidence - high volume - noncurrent - uniform thought } & Sorbello et al $2009^{55}$ \\
\hline There is strong evidence that increasing the intensity of rehabilitation & SIGN (20I0) & $1+$ & Van Peppen et al $2004^{58}$ \\
\hline \multirow[t]{13}{*}{ has beneficial effects on functional outcomes, including gait. } & & & Kwakkel et al $1997^{59}$ \\
\hline & & & Kwakkel et al $2004^{60}$ \\
\hline & USVA/Dod & $\mathrm{I}, \mathrm{B}$ & Kwakkel et al $1999^{56}$ \\
\hline & & & Langhorne et al $1996^{57}$ \\
\hline & & & Lincoln et al $1999^{61}$ \\
\hline & & & Parry et al $1999^{62}$ \\
\hline & & & Rapoport and \\
\hline & & & Judd-Van Eerd $1989^{63}$ \\
\hline & & & Richards et al $1993^{64}$ \\
\hline & & & Sivenius et al $1985^{65}$ \\
\hline & & & Smith et al $198 I^{66}$ \\
\hline & & & Sunderland et al $1992^{67}$ \\
\hline & & & Van der Lee et al $200 I^{67}$ \\
\hline \multicolumn{4}{|l|}{ Low volume - current } \\
\hline There is insufficient evidence that patients undergoing active rehabilitation & NSF & GPP & Intercollegiate Stroke \\
\hline should be provided with as much as possible; a minimum of I hour active & & & Working Party, $2008^{28}$ \\
\hline \multicolumn{4}{|l|}{ practice per day, at least 5 days a week for both physical and occupation } \\
\hline \multicolumn{4}{|l|}{$\begin{array}{l}\text { therapy. } \\
\text { Low volume - noncurrent }\end{array}$} \\
\hline $\begin{array}{l}\text { There is some evidence that rehabilitation should be structured to provide } \\
\text { as much practice as possible within the first } 6 \text { months after stroke. }\end{array}$ & NSF & A & Kwakkel et al $1999^{56}$ \\
\hline
\end{tabular}
as much practice as possible within the first 6 months after stroke.

\section{PARM Endorsements}

- PARM strongly endorses that stroke patients should be mobilized as early as possible; within 24 hours after onset of symptoms unless medically contraindicated.

- PARM strongly endorses that the intensity of rehabilitation should be increased according to the tolerance of patient and it has beneficial effects on functional outcome, including gait.

- PARM endorses that therapy should be given as much as needed and tolerated to re-establish pre-morbid or optimal level of functional independence.

- PARM recommends that there should be a structured rehabilitation program that will provide as much practice as possible within the first six months after stroke onset.

- PARM suggests that rehabilitation should be given for a minimum of one hour of active practice per day, five days a week, for both physical therapy and occupational therapy.

Note: The Philippine Academy of Rehabilitation Medicine summarized recommendations are timing, intensity, frequency, and duration of rehabilitation.

Abbreviations: CSS, Canadian Stroke Network and Heart and Stroke Foundation of Canada; GPP, good practice point; NSF, National Stroke Foundation; SIGN, Scottish Intercollegiate Guidelines Network; USVA/Dod, United States Department of Veterans Affairs/Department of Defense/American Heart Association.

provinces and remote islands of the Philippines this may not be possible because of limited access to skilled work force, limited finances, or large distances to travel. Thus the PARM context points (Table 6) provide strategies for optimizing rehabilitation in these situations, using alternative approaches to care delivery. Minimum standard of care may be applied in primary and secondary hospitals where the resources are limited while the additional standard of care 
Table 6 Philippine Academy of Rehabilitation Medicine (PARM) context points for minimal and additional standard care of practice for early inpatient rehabilitation

\begin{tabular}{|c|c|c|}
\hline & Minimum standard care of practice & Additional standard care of practice \\
\hline Equipment & Parallel bars, walking frame & $\begin{array}{l}\text { Biodex }^{\circledR} \text { machine frame } \\
\text { (Biodex Medical Systems, Shirley, NY) }\end{array}$ \\
\hline Workforce & $\begin{array}{l}\text { Trained personnel (physical therapist, } \\
\text { occupational therapist, nurse) }\end{array}$ & $\begin{array}{l}\text { Trained personnel (physical therapist, } \\
\text { occupational therapist, speech therapist, nurse) }\end{array}$ \\
\hline Resources & None & None \\
\hline Training & Within competency & Within competency \\
\hline When is it done & $\begin{array}{l}\text { Within } 24 \text { hours after onset of symptoms } \\
\text { or when medically stable }\end{array}$ & $\begin{array}{l}\text { Within } 24 \text { hours after onset of symptoms } \\
\text { or when medically stable }\end{array}$ \\
\hline $\begin{array}{l}\text { Reassessment using at least } \\
\text { one standard outcome measure }\end{array}$ & $\begin{array}{l}\text { Everyday discharge planning should be } \\
\text { documented in a discharge document }\end{array}$ & $\begin{array}{l}\text { Everyday discharge planning should be } \\
\text { documented in a discharge document }\end{array}$ \\
\hline
\end{tabular}

may be used in tertiary hospitals where there may be more sophisticated equipment, and more personnel are employed in the rehabilitation department.

PARM recommendations and PARM context points addressed the evaluation and diagnosis of low back pain, and pharmacologic, nonpharmacologic, and surgical treatment for acute, subacute, and chronic low back pain. For stroke, they included inpatient and outpatient stroke rehabilitation, secondary prevention of stroke, lower extremity interventions, upper extremity interventions, poststroke shoulder pain, cognitive disorders, apraxia, perceptual disorders, aphasia, dysphagia and aspiration poststroke, poststroke medical complications, depression in stroke, and community-based rehabilitation and reintegration.

\section{Implementation}

The PARM recommendations and context points for stroke rehabilitation and low back pain were presented at the PARM Annual Convention February 2012 (Baguio City, Philippines) to approximately $85 \%$ PARM members. Comments and criticisms were provided by PARM members in regard to improving the way the guidelines were presented, to assist in their uptake. Revisions to guideline wording were undertaken based on this feedback. The guidelines are currently undergoing public consultation. Electronic mails were sent to the PARM members to review the full version of the two contextualized guidelines. A link was provided in this email to a survey form seeking feedback on the guideline layout and construction, uptake, and PARM context points (Tables 7.1-7.3). The recommendations and context points are being critically reviewed by the members in order to identify errors and oversights, to give suggestions for their improvement; and to debate about their rationale if needed. ${ }^{32}$ Then, it will be sent to other relevant specialties' associations such as the Philippine Neurological Association and Philippine Physical Therapy Association for comments.

Table 7.I Survey underpinning evaluation of the Philippine Academy of Rehabilitation Medicine clinical practice guidelines: guideline layout and construction

\begin{tabular}{lllll}
$\begin{array}{l}\text { Strongly } \\
\text { agree }\end{array}$ & Agree & $\begin{array}{l}\text { Neither agree } \\
\text { nor disagree }\end{array}$ & Disagree & $\begin{array}{l}\text { Strongly } \\
\text { disagree }\end{array}$ \\
\hline
\end{tabular}

The guideline is simple to navigate

The layout of the guideline will encourage physiatrists to use it

The purpose of the guideline is clear

The end-users are clearly specified

The guideline group and their affiliations are provided

The methodological processes are clear

- Guideline identification and selection

- Inclusion and exclusion criteria

- Patient journey construction

- Guideline critical appraisal

- Mapping relevant guideline recommendations to the patient journey

- Summarizing strength of the evidence underpinning the recommendations

- Providing relevant references 
Table 7.2 Survey underpinning evaluation of the Philippine Academy of Rehabilitation Medicine clinical practice guidelines: guideline uptake

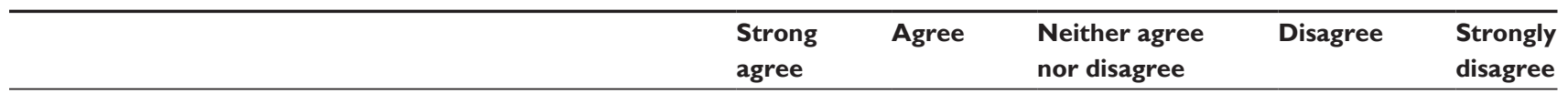

Use of this document could promote evidence-based practice

in stroke care in the Philippines

Any Filipino physiatrist could use this document

Use of this document could improve the quality of stroke care

in the Philippines

Use of this document could promote multidisciplinary practices

in stroke care in the Philippines

This will assist in promoting awareness of the clinical practice guidelines and the possible adoption of the recommendations of other medical and paramedical professionals.

\section{Discussion}

The concept of providing evidence-based health care practices in the Philippines is gaining momentum; however, there are many stakeholders (policy makers, managers, clinicians, and patients) who are still unfamiliar with the notion. Thus it was a higher priority for PARM to educate and involve as many stakeholders as possible in evidence-based practices and implement existing evidence (contextualized appropriately for local conditions) than to invest in developing de novo guidelines, which would be time consuming and financially restraining. However, there were several stumbling blocks for the PARM initiative in the initial contextualization process. One was the lack of guidance regarding how to do it, as the ADAPTE process provided insufficient guidance for the contextualization process. This was noted in particular in taking a standardized approach to writing endorsements and strategies (context points) for the included recommendations. ${ }^{10,11}$ Moreover, different standards and styles of writing by guideline developers and ways of summarizing the underpinning evidence base confused the (mostly) novices in guideline contextualization. It was this confusion that resulted in the production of the PARM writing guide (Tables 3 and 4). Finally, determining a typical Filipino patient journey took much longer than initially planned due to the variability in Filipino health care settings, health care provider availability and training, and resources.

One of strengths of the PARM approach is the innovative, simple, practical step-by-step method of contextualizing guidelines to the needs of a developing country. With these context points, the PARM group was able to concretize the endorsements and recommendations and has made the guidelines more culturally appropriate. It may also serve as a guide for health care professionals as to what would be the minimum requirement for equipment, personnel, and training but still of best evidence-based practice. The other strengths are the resource-efficient training process, the dedicated efforts of the working party, the tight timeline, and the structured processes which guided small group work.

\section{Conclusion}

PARM has taken a significant leadership step for developing countries, particularly those in Southeast Asia where health care delivery decisions are similarly led by doctors. The PARM efforts have produced an evidence implementation framework for Filipino health care providers, managers,

Table 7.3 Survey underpinning evaluation of the Philippine Academy of Rehabilitation Medicine clinical practice guidelines: Philippine Academy of Rehabilitation Medicine context points

\begin{tabular}{|c|c|c|c|c|c|}
\hline & $\begin{array}{l}\text { Strongly } \\
\text { agree }\end{array}$ & Agree & $\begin{array}{l}\text { Neither agree } \\
\text { nor disagree }\end{array}$ & Disagree & $\begin{array}{l}\text { Strongly } \\
\text { disagree }\end{array}$ \\
\hline \multicolumn{6}{|l|}{ The PARM context points deal with important issues which may } \\
\hline \multicolumn{6}{|l|}{ The PARM context points will assist physiatrists to identify and } \\
\hline \multicolumn{6}{|l|}{ provided to Filipino stroke patients } \\
\hline $\begin{array}{l}\text { The PARM context points will support better training at } \\
\text { undergraduate and postgraduate levels regarding evidence-based } \\
\text { practice }\end{array}$ & & & & & \\
\hline
\end{tabular}

Abbreviation: PARM, Philippine Academy of Rehabilitation Medicine. 
policy makers, and patients that supports best practice care decisions and health service delivery. This framework for evidence adoption will improve the efficiency of efforts by other Filipino groups and groups in other developing countries, particularly in situations where there is no need for de novo guideline development. Efficiencies of the PARM approach include the specific writing guide, the use of the patient journey as a way of mapping evidence-based practice to critical points, the mechanism of constructing summary tables of recommendations when more than one current high-quality guideline is relevant and available, and the mechanism of summarizing accompanying references and strength of evidence statements underpinning references. This approach allows evidence-based practice initiatives to focus on applicability and generalizability of relevant recommendations to the average patient journey within their local context. The only de novo writing required in the PARM approach is producing the PARM endorsements and context points.

\section{Acknowledgments}

The authors thank C Valdecanas, S Aycardo, E Berredo, R Cembrano, R Cunanan, E Dizon, E Gambito, J Macalintal, and E Noche-Cabungcal for their contributions to the Low Back Pain Clinical Practice Guideline working committee. The authors thank M Benigno, M Estrada, E Gaw, E Martinez, G Montes, J Montes, E Orayle, C Quilino, MTangco, E Uyehara, A Virtucio, and M Zamora for their contributions to the Stroke Rehabilitation Clinical Practice Guideline Working Committee.

\section{Disclosure}

The authors report no conflicts of interest in this work.

\section{References}

1. Field MJ, Lohr KN, editors. Guidelines for Clinical Practice: From Development to Use. Washington, DC: National Academy Press; 1992.

2. Scottish Intercollegiate Guideline Network (SIGN) [website on the Internet]. Edinburgh: National Health Service; 2011 [updated February 27, 2012]. Available from: http://www.sign.ac.uk/. Accessed March 15, 2012.

3. New Zealand Guideline Group (NZGG) [website on the Internet]. Wellington: New Zealand Guideline Group; 2001. Available from: http:// www. nzgg.org.nz/. Accessed March 15, 2012.

4. National Health and Medical Research Council [website on the Internet]. Canberra: National Health and Medical Research Council; 2012. Available from: http://www.nhmrc.gov.au. Accessed March 15, 2012.

5. National Institute for Health and Clinical Excellence [website on the Internet]. Available from: http://www.nice.org.uk. London: National Health Service; 2001. Accessed March 15, 2012.

6. Turner T, Misso M, Harris C, Green S. Development of evidence-based clinical practice guidelines (CPGs): comparing approaches. Implement Sci. 2008;3:45.

7. Kumar SK, Young A, Lizarondo L. What's in a name? Current case of nomenclature confusion. In: Grimmer-Somers K, Worley A, editors. Practical Tips for Using and Developing Guidelines: An Allied Health Primer. Manila: University of Santo Thomas Publishing House; 2010. 1-4.
8. AGREE: advancing the science of practice guidelines [website on the Internet]. London: Agree Research Trust; 2010. Available from: http:// www.agreetrust.org. Accessed March 15, 2012.

9. Shiffman RN, Dixon J, Brandt C, et al. The GuideLine Implementability Appraisal (GLIA): development of an instrument to identify obstacles to guideline implementation. BMC Med Inform Decis Mak. 2005;5:23.

10. ADAPTE. The ADAPTE collaboration. 2007. Available from: http:// www.adapte.org/www/rubrique/the-adapte-collaboration.php. Accessed March 15, 2012.

11. Harrison MB, Legare F, Graham ID, Fervers B. Adapting clinical practice guidelines to local context and assessing barriers to their use. CMAJ. 2010;182(2):E78-E84.

12. Guyatt GH, Oxman AD, Schunemann HJ, Tugwell P, Knotterus A. GRADE guidelines: a new series of articles in the Journal of Clinical Epidemiology. J Clin Epidemiol. 2010;64(4):380-382.

13. Hillier S, Grimmer-Somers K, Merlin T, et al. FORM: an Australian method for formulating and grading recommendations in evidencebased clinical guidelines. BMC Med Res Methodol. 2011;11:23.

14. Grimshaw JM, Thomas RE, MacLennan G, et al. Effectiveness and efficiency of guideline dissemination and implementation strategies. Health Technol Assess. 2004;8(6):1-72.

15. Graham ID, Harrison MB, Brouwers M, Davies BL, Dunn S. Facilitating the use of evidence in practice: evaluating and adapting clinical practice guidelines for local use by health care organizations. J Obstet Gynecol Neonatal Nurs. 2002;31(5):599-611.

16. Eccles M, Grimshaw J, Walker A, Johnston M, Pitts N. Changing the behavior of healthcare professionals: the use of theory in promoting the uptake of research findings. J Clin Epidemiol. 2005;58(2):107-112.

17. Encarta dictionary. Available from: http://www.wordiq.com/definition/ Encarta_Webster's_Dictionary. Accessed March 15, 2012.

18. World Health Organization. Countries: Philippines. 2012. Available from: http://www.who.int/countries/Phl/en/. Accessed March 15, 2012.

19. World Health Organization. Countries: Australia. 2012. Available from: http://www.who.int/countries/aus/en/. Accessed March 15, 2012.

20. Anderson B, Alcantara MO. Technical assistance to the Republic of Philippines for the health sector development program ADB TA 4647-PHI: final report. 2007. Available from: http://www2.adb.org/Documents/Reports/ Consultant/39066-PHI/39066-PHI-TACR.pdf. Accessed March 15, 2012.

21. Republic of the Philippines Department of Health. National objectives for health: Philippines 2005-2010. October 2005. Available from: http://www.doh.gov.ph/sites/default/files/NOH2005.pdf. Accessed March 15, 2012.

22. Lu H, Javier F. Prevalence and treatment of chronic pain in the Philippines. Phil J Int Med. 2011;49(2):61-69.

23. National Guideline Clearinghouse [website on the Internet]. Rockville: Agency for Healthcare Research and Quality; 2012. Available from: http://www.guideline.gov/. Accessed March 15, 2012.

24. International Center for Allied Health Evidence. The iCAHE guideline checklist. 2009. Available from: http://www.unisa.edu.au/cahe/ Resources/GuidelineCH/iCAHE_guideline_checklist.pdf. Accessed March 15, 2012.

25. Fervers B, Burgers JS, Voellinger R, et al. Guideline adaptation: an approach to enhance efficiency in guideline development and improve utilisation. BMJ Qual Saf. 2011;20(3):228-236.

26. Doumit G, Gattellari M, Grimshaw J, O’Brien MA. Local opinion leaders: effects on professional practice and health care outcomes. Cochrane Database Syst Rev. 2007;1:CD000125.

27. World Ophthalmology Leaders Forum in Education; American Academy of Ophthalmology. Guidelines for developing guidelines. Consensus versus clinical trials: where is the future? November 2007. Available from: http://www.aao.org/international/upload/WOLFESummary-1107.pdf. Accessed March 15, 2012.

28. Intercollegiate Stroke Working Party. National Clinical Guidelines for Stroke. 3rd ed. London: Royal College of Physicians; 2008.

29. Khadilkar A, Phillips K, Jean N, Lamothe C, Milne S, Sarnecka J. Ottawa panel evidence-based clinical practice guidelines for post-stroke rehabilitation. Top Stroke Rehabil. 2006;13(2):1-269. 
30. Donabedian A. The quality of care. How can it be assessed? JAMA. 1988;260(12):1743-1748.

31. Hoffmann T, Bennett S, Del Mar C. Introduction to evidence-based practice. In: Hoffmann T, Bennett S, Del Mar C, editors. Evidence-based Practice Across the Health Professions. Sydney: Churchill Livingstone; 2012:1-15.

32. Shekelle P, Woolf S, Grimshaw JM, Schunemann HJ, Eccles MP. Developing clinical practice guidelines: reviewing, reporting, and publishing guidelines; updating guidelines; and the emerging issues of enhancing guideline implementability and accounting for comorbid conditions in guideline development. Implement Sci. 2012;7(1):62.

33. Negrini S, Giovannoni S, Minozzi S, et al. Diagnostic therapeutic flowcharts for low back pain patients: the Italian clinical guidelines. Eura Medicophys. 2006;42(2):151-170.

34. National Institute for Health and Clinical Excellence. Low back pain: early management of persistent non-specific low back pain. May 2009. Available from: http://publications.nice.org.uk/low-back-pain-cg88. Accessed March 15, 2012.

35. Toward Optimized Practice. Guideline for the evidence-informed primary care management of low back pain. 2009. Available from: http:// www.topalbertadoctors.org/cpgs.php?sid $=65 \&$ cpg_cats $=90$. Accessed March 15, 2012.

36. Montreal Public Health Department. CLIP practice guideline: clinic on low-back pain in interdisciplinary practice. 2007. Available from: http://collections.banq.qc.ca/ark:/52327/bs47125. Accessed March 15, 2012.

37. Institute for Clinical Systems Improvement. Health care guideline: adult acute and subacute low back pain. January 2012. Available from: http:// www.icsi.org/low_back_pain/adult_low_back_pain_8.html. Accessed March 15, 2012.

38. WorkCoverSA. Acute-subacute low back pain. 2010. Available from: http://www.workcover.com/site/treat_home/guidelines_by_injury_type/ acutesubacute_low_back_pain.aspx. Accessed March 15, 2012.

39. Chou R, Qaseem A, Snow V, et al. Diagnosis and treatment of low back pain: a joint clinical practice guideline from the American College of Physicians and the American Pain Society. Ann Intern Med. 2007;147(7):478-491.

40. Chou R, Loeser J, Owens D, et al. Interventional therapies, surgery, and interdisciplinary rehabilitation for low back pain: an evidence-based clinical practice guideline from the American Pain Society. Spine (Phila Pa 1976). 2009;34(10):1066-1077.

41. Canadian Stroke Strategy. Canadian best practice recommendations for stroke care (update). December 8, 2010. Available from: http://www.hsf. sk.ca/siss/documents/2010_BP_ENG.pdf. Accessed March 15, 2012.

42. National Stroke Foundation - Australia. Clinical guidelines for stroke management. 2010. Available from: http://strokefoundation.com.au/ health-professionals/tools-and-resources/clinical-guidelines-for-strokeprevention-and-management/. Accessed March 15, 2012.

43. Scottish Intercollegiate Guidelines Network. Management of patients with stroke: rehabilitation, prevention and management of complications, and discharge planning. 2010. Available from: http://www.sign. ac.uk/guidelines/fulltext/118/index.html. Accessed March 15, 2012.

44. Scottish Intercollegiate Guidelines Network. Management of patients with stroke: identification and management of dysphagia. 2011. Available from: http://www.sign.ac.uk/guidelines/fulltext/119/index.html. Accessed March 15, 2012.

45. Department of Veterans Affairs; Department of Defense; American Heart Association; American Stroke Association. Management of stroke rehabilitation. 2010. Available from: http://www.healthquality.va.gov/ stroke/stroke_full_221.pdf. Accessed March 15, 2012.

46. Bernhardt J, Chitravas N, Meslo IL, Thrift AG, Idredavik B. Not all stroke units are the same: a comparison of physical activity patterns in Melbourne Australia and Trondhelm Norway. Stroke. 2008;39(7):2059-2065.

47. Langhorne P, Holmqvist LW, Early Supported Discharge Trialists. Early supported discharge after stroke. J Rehabil Med 2007;39(2):103-108.
48. Cifu DX, Stewart DG. Factors affecting functional outcome after stroke: A critical review of rehabilitation interventions. Arch Phys Med Rehab. 1999;80(5 Suppl 1):S35-S39.

49. Gagnon D, Nadeau S, Tam V. Ideal timing to transfer from an acute care hospital to an interdisciplinary inpatient rehabilitation program following a stroke: An exploratory study. BMC Health Services Research. 2006;6:151

50. Ottenbacher KJ, Jannell S. The results of clinical trials in stroke rehabilitation research. Arch Neurol. 1993;50(1):37-44.

51. Maulden SA, Gassaway J, Horn SD, Smout RJ, DeJong G. Timing of initiation of rehabilitation after stroke. Arch Phys Med Rehabil. 2005;86(12 Suppl 2):S34-S40.

52. Musicco M, Emberti L, Nappi G, Caltagirone C. Early and long-term outcome of rehabilitation in stroke patients: the role of patient characteristics, time of initiation, and duration of interventions. Arch Phys Med Rehabil. 2003;84:551-558.

53. Paolucci S, Antonucci G, Grasso MG, Morelli D, Troisi E, Coiro P, et al. Early versus delayed inpatient stroke rehabilitation: A matched -comparison conducted in Italy. Arch Phys Med Rehabil. 2000;81(6):695-700.

54. Wade DT, Collen FM, Robb GP, Warlow CP. Physiotherapy intervention late after stroke and mobility. Brit Med J. 1992;304(6827):609-613.

55. Sorbello D, Dewey HM, Churilov L, Thrift AG, Collier JM, Donnan G, Bernhardt J. Very early mobilisation and complications in the first 3 months after stroke: Further results from phase II of a very early rehabilitation trial (AVERT). Cerebrovasc Dis. 2009;28(4): 378-383.

56. Kwakkel G, Wagenaar RC, Twisk JW, Lankhorst GJ, Koetsier JC. Intensity of leg and arm training after primary middle-cerebral-artery stroke: A randomised trial. Lancet. 1999;354(9174):191-196.

57. Langhorne P, Wagenaar R, Partridge C. Physiotherapy after stroke: More is better? Physiother Res Int. 1996;1(2):75-88.

58. Van Peppen RP, Kwakkel G, Wood-Dauphinee S, Hendriks HJ, Van der Wees PJ, Dekker J. The impact of physical therapy on functional outcomes after stroke: What's the evidence? Clin Rehabil. 2004;18(8):833-862.

59. Kwakkel G, Wagenaar RC, Koelman TW, Lankhorst GJ, Koetsier JC. Effects of intensity of rehabilitation after stroke. A research synthesis. Stroke. 1997;28(8):1550-1556.

60. Kwakkel G, van Peppen R, Wagenaar RC, Wood Dauphinee S, Richards C, Ashburn A, et al. Effects of augmented exercise therapy time after stroke: A meta-analysis. Stroke. 2004;35(11):2529-2539.

61. Lincoln NB, Parry RH, Vass CD. Randomized, controlled trial to evaluate increased intensity of physiotherapy treatment of arm function after stroke. Stroke. 1999;30 (3):573-579.

62. Parry RH, Lincoln NB, Vass CD. Effect of severity of arm impairment on response to additional physiotherapy early after stroke. Clin Rehabil. 1999;13(3):187-198.

63. Rapoport J, Judd-Van Eerd M. Impact of physical therapy weekend coverage on length of stay in an acute care community hospital. Phys Ther. 1989;69(1):32-37.

64. Richards CL, Malouin F, Wood-Dauphinee S, Lindeman E, Kwakkel G. Task-specific physical therapy for optimization of gait recovery in acute stroke patients. Arch Phys Med Rehabil. 1993;74(6):612-620.

65. Sivenius J, Pyorala K, Heinonen OP, Salonen JT, Riekkinen P. The significance of intensity of rehabilitation of stroke--a controlled trial. Stroke. 1985;16(6):928-931.

66. Smith DS, Goldenberg E, Ashburn A, Kinsella G, Sheikh K, Brennan PJ, et al. Remedial therapy after stroke: a randomised controlled trial. Brit Med J (Clin Res Ed). 1981;282(6263):517-520.

67. Sunderland A, Tinson DJ, Bradley EL, Tinson D, Hewer RL, Wade DT. Enhanced physical therapy improves recovery of arm function after stroke. A randomised controlled trial. J Neurol Neurosurg Psychiat. 1992;55(7):530-535.

68. Van der Lee JH, Snels IA, Beckerman H, Lankhorst GJ, Wagenaar RC, Bouter LM. Exercise therapy for arm function in stroke patients: A systematic review of randomized controlled trials. Clin Rehabil. 2001;15(1):20-31. 
Journal of Healthcare Leadership

Dovepress

\section{Publish your work in this journal}

The Journal of Healthcare Leadership is an international, peer-reviewed, open access journal focusing on leadership for the health profession. The journal is committed to the rapid publication of research focusing on but not limited to: Healthcare policy and law; Theoretical and practical aspects healthcare delivery; Interactions between healthcare and society and evidence-based practices;

Interdisciplinary decision-making; Philosophical and ethical issues; Hazard management; Research and opinion for health leadership; Leadership assessment. The manuscript management system is completely online and includes a very quick and fair peer-review system. Visit http://www.dovepress.com/ testimonials.php to read real quotes from published authors.

Submit your manuscript here: http://www.dovepress.com/journal-of-healthcare-leadership-journal 